\section{Summary}

The excretion of iron in the urine has been studied before and during treatment with a new chelating agent for iron, desferrioxamine.

Three male subjects with presumably normal iron stores showed an increased iron excretion of 1 to $1.5 \mathrm{mg}$. of iron after $600 \mathrm{mg}$. of the chelate.

Patients with various types of iron overload all showed a marked increase in iron excretion when the material was given parenterally (8 to $33 \mathrm{mg}$. $/ \mathrm{g}$. of chelate).

A similar effect was noted in one subject with siderosis given D.T.P.A.

The possible therapeutic uses of such chelating agents are discussed.

We are grateful to the Geigy Company for supplies of D.T.P.A. and to Ciba Ltd., of Horsham and Basle, for a generous supply of desferrioxamine $B$ and for unpublished information about this material. We also thank Professor L. J. Witts and Dr. E. M. Buzzard for permission to study patients under their care.

\section{REFERENCES}

Bickel, H., Gäumann, E., Keller-Schierlein, W., Prelog, V., Vischer, E., Wrttstein, A., and Zähner, H. (1960). Experientia (Basel), 16, 129 .
Botbwell, T. H., and Mallett, B. (1955). Biochem. J., 59, 599

Callender, S. T., Mallett, B. J., and Smith, M. D. (1957). Brit. J. Haemat., 3, 186.

Fahey, J. L., Rath, C. E., Princiotto, J. V., Brick, I. B., and Rubin, M. (1961). J. Lab. clin. Med., 57, 436

Finch, S. C., and Finch, C. A. (1955). Medicine (Baltimore), 34, 381 .

Huff, R. L., Hennessy, T. G., Austin, R. E., Garcia, J. F., Roberts, B. M., and Lawrence, J. H. (1950). J. clin. Invest. 29, 1041.

Lancet, 1962.11172.

Maier, C. (1961). Report compiled by Dr. P. Imhof, of Ciba, Basle, on a meeting of Clinical Investigators, November 16, 1961.

Ohlsson, W. T. L., Kullendorff, G. T., and Ljungberg, K. L. (1953). Acta med. scand., 145, 410.

Pitcher, C. S. (1961). Report compiled by Dr. P. Imhof, of Ciba Basle, on a meeting of Clinical Investigators, November 16, 1961 .

Seven, M. J., Gottlieb, H., Israel, H. L., Reinhold, J. G., and Rubin, M. (1954). Amer. J. med. Sci., 228, 646.

Smith, C. H., Erlandson, M. E., Stern, G., Schulman, I. (1960). Blood, 15, 197.

Smith, R. S. (1962). Brit. med. J., 2, 1577.

Vischer, E. (1961). Report compiled by Dr. P. Imhof, of Ciba, Basle, on a meeting of Clinical Investigators, November 16, 1961.

Von Schnack, H. (1961). Ibid.

Wöhler, F. (1961). Ibid.

(1962). Proceedings of 8th Congress of European Society of Haematology, Vienna, 1961, 1, 244. Karger, Basle and New York.

\title{
IRON EXCRETION IN THALASSAEMIA MAJOR AFTER ADMINISTRATION OF CHELATING AGENTS
}

BY

\section{R. SEPHTON SMITH, M.A., M.B., B.Chir.}

From the Department of Haematology, the Hospital for Sick Children, Great Ormond Street, London

Blood transfusion is at present the only treatment for the refractory anaemia of thalassaemia major, and by this means, together with improved general medical care, the survival of children with this condition can be greatly prolonged. As a consequence iron accumulates from the repeated transfusions, together with that absorbed from food, and is deposited in the tissues. Eventually impaired organ function and pathological changes closely resembling those of idiopathic haemochromatosis may be found (Whipple and Bradford, 1936; Ellis et al., 1954 ; Witzleben and Wyatt, 1961).

Removal of significant quantities of iron from these children would represent a major advance in treatment. Recently two new chelating agents have been introduced which have a high affinity for iron, and both have been shown to promote significant iron excretion when given parenterally to adults with iron overloading due to haemochromatosis or transfusion haemosiderosis Fahey et al. (1961) reported the use of trisodium calcium diethylenetriamine-penta-acetate (D.T.P.A.) in three patients, including one 33-year-old woman with thalassaemia and transfusion haemosiderosis. More recently, iron excretion following the administration of desferrioxamine (" desferal ") to a number of adults with haemochromatosis or transfusion haemosiderosis has been reported (Ciba, 1961 ; Bannerman et al., 1962b). In the present study urinary iron excretion was measured in a group of thalassaemic children following parenteral doses of desferrioxamine or D.T.P.A.

\section{Materials and Methods}

Of the 18 patients studied 17 were classical cases of thalassaemia major. All had a refractory anaemia with a greatly increased proportion of alkali-resistant haemoglobin, hepatosplenomegaly, and radiological bone changes. The majority had been transfused at regular intervals, and some showed clinical evidence of iron overloading. One patient with congenital pure red-cell aplasia (Case 18) who had been regularly transfused since the age of 3 months is also included. Relevant details are shown in Table $I$.

As supplies of desferrioxamine and D.T.P.A. were limited, it was decided initially to study the effect of single treatments in a fairly large group; later it became possible to study the effect of repeated doses in a few patients. The chelating agents were usually given intravenously at the time of blood transfusion. When a patient received several treatments, these were given with successive transfusions at intervals of 5 to 12 weeks, depending on the patient's transfusion requirements. Half the dose was usually given immediately before transfusion, and the remainder afterwards : in each case it was given by slow infusion in $100-400 \mathrm{ml}$. of saline, according to the size of the child. Infusions of $100 \mathrm{mg}$. in Case 4 and of $200 \mathrm{mg}$. in Case 18 were given undivided before transfusion.

In a few patients desferrioxamine was given intramuscularly ; it was found that $200 \mathrm{mg}$. could be dissolved in $3 \mathrm{ml}$. of saline. In Cases 4 and 18 the intramuscular dose was given three days before an equal intravenous dose ; the repeated intramuscular doses in Case 6 were given on successive days, and in Case 10 the two intramuscular doses were given 24 and 48 hours after the intravenous infusion. At first $100-400 \mathrm{mg}$. of desferrioxamine was given, as preliminary experience in adults suggested that no additional advantage was gained by increasing the dose above $800 \mathrm{mg}$. (Ciba, 1961). D.T.P.A. was given in doses of $500-2,000 \mathrm{mg}$. in view of the experience of Fahey et al. (1961), who used doses of $2,500-4,000 \mathrm{mg}$. in adults. 
TABLE I.-Iron Excretion after Administration of Chelating Agents

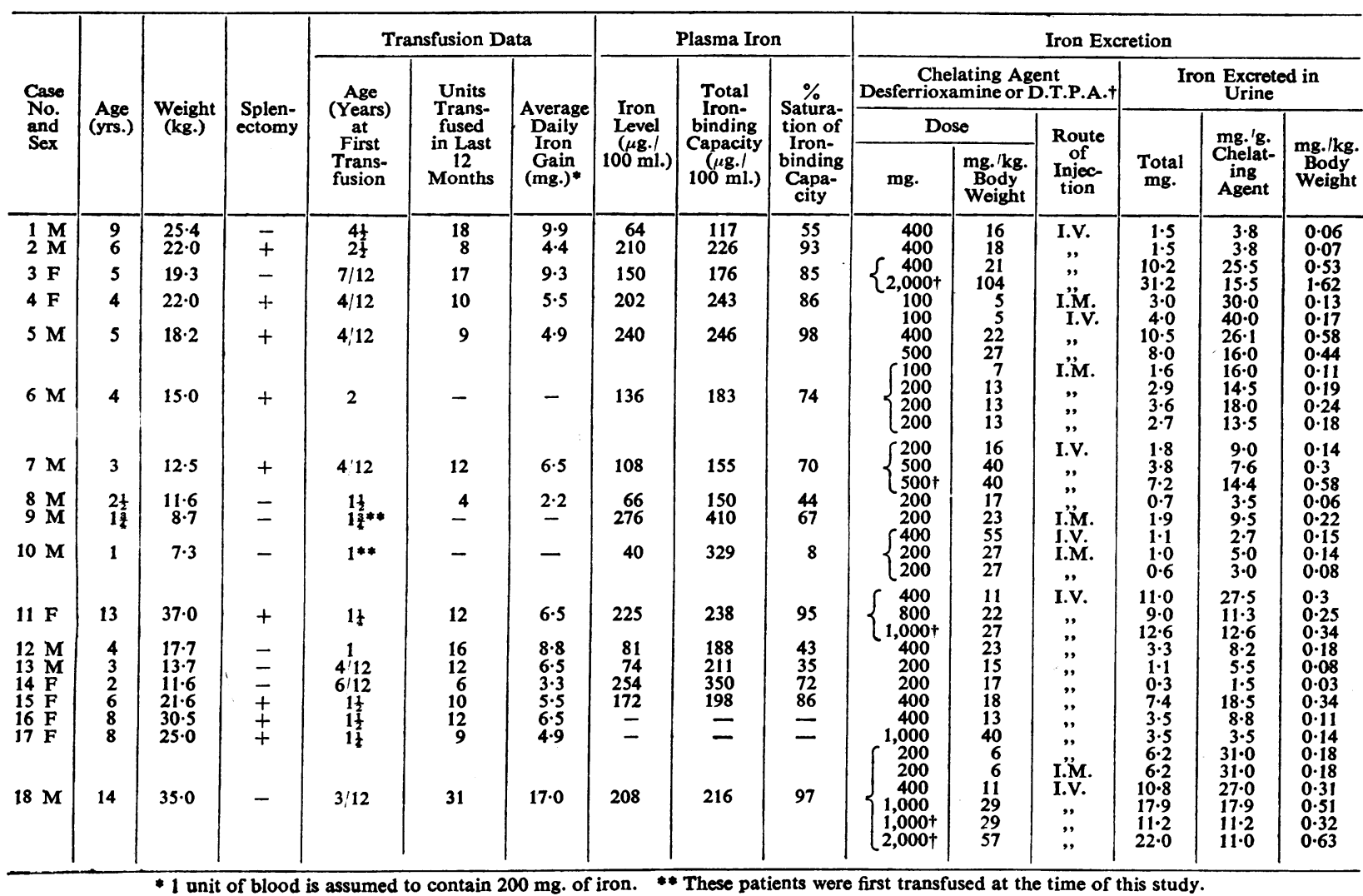

After administration of the chelating agent urine was collected into iron-free " polythene" bottles. The polythene tubing and bags used for the collection of urine from infants were shown to be free of iron. At first urine was collected for three to five days ; more recently collection has been restricted to a single 24 -hour period after administration of the chelating agent, as it became clear from the earlier estimations that excretion of the iron-chelate complex was complete within this period. This finding is consistent with the low molecular weight of both chelating agents (Table II). Chemical estimation of iron in the urine was carried out colorimetrically, using a modification of the plasma-iron method of Bothwell and Mallett (1955). Four ml. of urine, or $2 \mathrm{ml}$. of urine $+2 \mathrm{ml}$. of water, was substituted for the $4 \mathrm{ml}$. of plasma, and a urine blank was included. Plasma iron and iron-binding capacity were measured by the methods of Ramsay (1957).

TABLE II.-Properties of Desferrioxamine and D.T.P.A.

\begin{tabular}{l|c|c|c}
\hline & $\begin{array}{c}\text { Molecular } \\
\text { Weight }\end{array}$ & $\begin{array}{c}\text { Iron-binding } \\
\text { Capacity } \\
\text { (mg./100 mg.) }\end{array}$ & $\begin{array}{c}\text { Stability } \\
\text { Constant of } \\
\text { Iron Complex }\end{array}$ \\
\hline $\begin{array}{c}\text { Desferrioxamine (Ciba, 1961) } \\
\text { D.T.P.A. (Fahey et al., 1961) }\end{array}$ & 497 & $\begin{array}{c}9 \cdot 4 \\
11.2\end{array}$ & $10^{30.7}$ \\
\hline
\end{tabular}

Transferrin, which has two iron-binding sites, forms complexes with stability constants of $10^{27}$ and $10^{29}$

Results

Iron excretion was measured in six of the children before the chelating agent was given: values varying between 0.15 and $0.6 \mathrm{mg}$. $(0.02-0.034 \mathrm{mg}$. $/ \mathrm{kg}$. body weight) in 24 hours were obtained.

The results following the administration of chelating agents are shown in Table $I$. It can be seen that iron excretion varies greatly. There is also wide variation in the size of the dose used and in the weight of the children ; in order to compare the levels of iron excretion in children of varying size the dose used and iron excretion are both expressed in terms of body weight. Observations following the use of both desferrioxamine and D.T.P.A. are considered together, as sufficient data have not yet been obtained to allow a comparative study. It will be noted, however, that both chelating

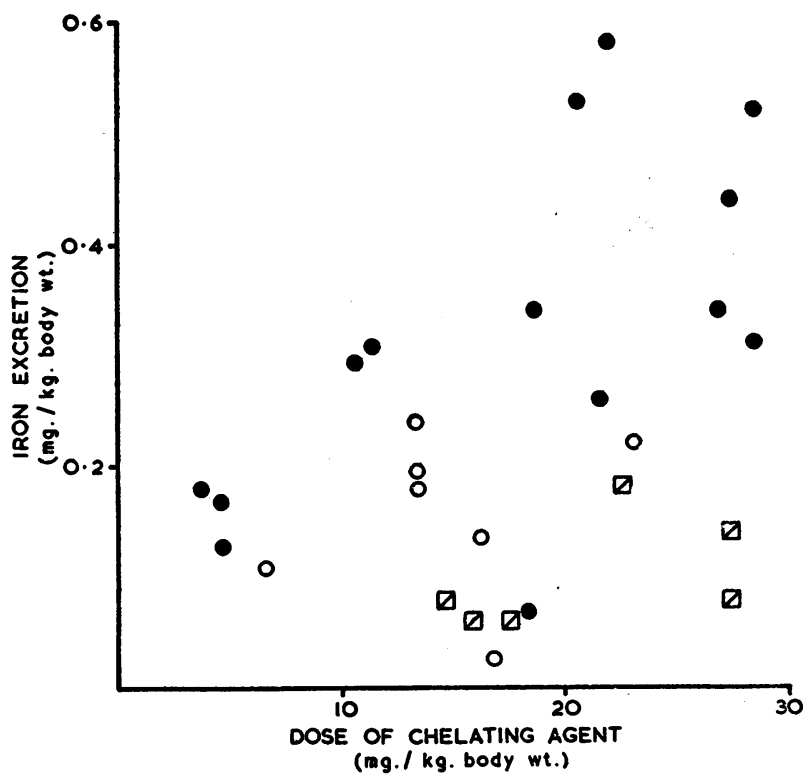

Relationship of iron excretion to degree of saturation of plasma iron-binding protein. $=$ Over $80 \%$ saturated iron-binding capacity. $O=60-80 \%$. $\quad \square=$ Under $60 \%$. 
agents have similar properties (Table II); comparable levels of iron excretion might therefore be expected after the administration of either agent. The dose of chelating agent used varied between $100 \mathrm{mg}$. and $2 \mathrm{~g}$. (5-104 mg. $/ \mathrm{kg}$. body weight). In patients with over $80 \%$ saturation of the plasma iron-binding capacity, with one exception, iron excretion varied between 11 and $40 \mathrm{mg}$. $/ \mathrm{g}$. of desferrioxamine or D.T.P.A. In contrast, iron-excretion levels well below $8 \mathrm{mg}$. $/ \mathrm{g}$. of chelating agent were usually found in patients with under $60 \%$ saturation of the plasma iron-binding capacity. An intermediate degree of iron excretion was found in patients with $60-80 \%$ saturation of the plasma ironbinding capacity. The dose of chelating agent is plotted against the iron excretion found in these three groups of patients (see Fig.) For convenience, six observations in which more than $30 \mathrm{mg}$. of chelating agent per $\mathrm{kg}$. body weight was given are excluded.

\section{Discussion}

It is of great interest that the level of iron excretion after the administration of chelating agents is related to the degree of saturation of the plasma iron-binding protein. A high plasma iron with little unsaturated iron-binding capacity usually indicates increased iron stores, and it will be noted that in this study the highest degree of saturation of the iron-binding protein is seen in the older children who had received regular transfusions, starting in infancy; these children excreted significantly more iron, even in proportion to their weight, than those younger ones who had received fewer or no transfusions. Among those few older children who excreted little iron, one (Case 1) had only $55 \%$ saturation of the plasma ironbinding protein, and had not required transfusion until the age of $4 \frac{1}{2}$ years ; another (Case 17), in whom plasmairon determinations were not done, was transfused for only one year before splenectomy at the age of $2 \frac{1}{2}$ years, after which transfusions were not required for four years. It therefore seems probable that there was no great excess of iron storage in these two children, both of whom also showed negligible iron excretion.

These observations suggest that significant iron excretion will be achieved in this way only in patients who already have an excess of stored iron. This is in agreement with the findings of Fahey et al. (1961) in patients with haemochromatosis and their siblings, and lends further support to the view that it is only stored iron, present in great excess, which can be mobilized and excreted after the administration of chelating agents. The pathways of normal iron metabolism are evidently not influenced by them, and so far there is no evidence that either desferrioxamine or D.T.P.A. is able to remove iron from the plasma transferrin, or from red blood cells or their precursors.

It seems possible that the chelating agents may be of practical value in two distinct ways - as a diagnostic test and as a therapeutic measure. The degree of correlation between iron excretion and iron overloading found in the present study suggests that the measurement of iron excretion after a single test dose of either desferrioxamine or D.T.P.A. may be of diagnostic value in patients with suspected iron overload. The practical therapeutic value of these chelating agents cannot yet be fully assessed. It can be seen from Table I that iron excretion after a single dose may be little greater than the average daily gain in iron from transfused red cells. Repeated intravenous infusion is not practicable in these thalassaemic children, but it is intended to treat some of the most heavily iron-laden children by daily intramuscular injections of desferrioxamine, in order to find out whether a useful level of iron excretion can be maintained.

The limited evidence available (Cases 4 and 18) suggests that the intramuscular route is effective, and so far none of the children treated in this way has experienced any local reaction to the injections. It is clear, however, that the volume of the injections $(3 \mathrm{ml} . /$ $200 \mathrm{mg}$.) may present problems in the smaller children, many of whom have poorly developed muscle masses, if substantially larger doses are necessary. None of the children have so far received intramuscular D.T.P.A., in view of reports of pain at the site of injection (Bannerman et al., $1962 \mathrm{~b}$; C. S. Pitcher, personal communication 1962). On the other hand, Fahey et al., (1961) found that intramuscular injections of D.T.P.A. were well tolerated, and if this is so they might be extremely valuable in children, as $250 \mathrm{mg}$. can be given in a volume of $1 \mathrm{ml}$.

The dose-response relationship found in the most heavily iron-laden group (see Fig.) suggests that it may be advantageous to increase the dose of the chelating agent substantially. All but one of these children excreted between 11 and $40 \mathrm{mg}$. of iron per $\mathrm{g}$. of desferrioxamine or D.T.P.A. given, when doses of less than $30 \mathrm{mg} / \mathrm{kg}$. body weight were used. Whether comparable increases in iron excretion may be obtained by increasing the dose beyond this level remains to be seen. It is of interest to note that one child (Case 3) excreted $15.5 \mathrm{mg}$. of iron per g. of D.T.P.A. (1.62 mg./ $\mathrm{kg}$. body weight) when given a dose $(2 \mathrm{~g}$.$) , equivalent$ to $104 \mathrm{mg} . / \mathrm{kg}$. body weight. It can be stated that no side-effects have been noted in any of these children following the intravenous infusion of desferrioxamine or D.T.P.A., even when comparatively high doses were used. As the opportunity for an intravenous infusion occurs every one to three months, at the time of blood transfusion, it is clearly desirable to use the maximum effective dose on these occasions if intravenous therapy is to be of any practical value. Several workers have suggested that no advantage is to be gained by increasing the dose of desferrioxamine above $800 \mathrm{mg}$. (about 10-15 $\mathrm{mg}$. $/ \mathrm{kg}$. body weight) in adult patients (Ciba, 1961), but the present findings suggest that the maximum useful dose in children may be much higher than this.

It will be of interest to determine whether desferrioxamine and D.T.P.A. are equally effective. Equal doses of each chelating agent were used in only two patients (Case 7 and 18); one showed rather higher iron excretion following D.T.P.A., the other following desferrioxamine. On theoretical grounds it might be expected that little difference would be found: one atom of iron is thought to be bound by one molecule of either chelating agent; both have molecular weights of the same order, and form complexes with iron which have similar stability to the transferrin-iron complex (Table II). Both desferrioxamine and D.T.P.A. are excreted rapidly, and there is no evidence that they interfere with calcium metabolism. Desferrioxamine does not bind calcium, and D.T.P.A. is given as calcium salt: it appears to exchange its atom of calcium for an atom of iron.

It is possible that increased intravenous doses, perhaps combined with courses of intermittent intramuscular injections, may still fail to remove quantities of iron approaching the amount received in transfusions. Removal of even minimal quantities of iron by chelation 
may be beneficial, however ; in observations on patients with haemochromatosis it has been noticed on several occasions that the subjective improvement and reduction in pigmentation after desferrioxamine infusions was far greater than expected, in view of the relatively small quantities of iron removed (Ciba, 1961). Finally, the removal of iron by chelation must be considered in relation to other aspects of the patient's iron metabolism. There is evidence that in thalassaemia major iron is absorbed from food in amounts greater than can be used in haemoglobin synthesis. At necropsy iron may be found in quantities far greater than can be accounted for by transfusions (Ellis et al., 1954). Even when iron overload is present, some degree of iron absorption persists (Erlandson et al., 1962 ; Bannerman et al., 1962a). It is therefore probable that iron absorption from food makes a significant contribution to the iron overload present in these patients. Means will have to be found to reduce their absorption of food iron; indeed it might be found that removal of significant amounts of stored iron by parenteral chelating agents was followed by enhanced iron absorption from food, in which case no overall benefit would result. It is clear that a great deal of further work will be required, particularly in the development of chelating agents which can be taken by mouth, some to bind food iron and prevent its absorption, others to be absorbed unchanged for the purpose of binding excess iron in the body stores.

\section{Summary}

Iron excretion was measured in 17 thalassaemic children and one boy with pure red-cell aplasia after the intravenous or intramuscular administration of desferrioxamine or D.T.P.A.

The dose of chelating agent varied between $100 \mathrm{mg}$. and $2 \mathrm{~g}$. (5-104 mg./kg. body weight). Children with over $80 \%$ saturation of the plasma iron-binding capacity excreted (with one exception) 11-40 mg. of iron per g. of desferrioxamine or D.T.P.A. given : those with less than $60 \%$ saturation usually excreted less than $8 \mathrm{mg} . / \mathrm{g}$., and an intermediate degree of iron excretion was found in children with $60-80 \%$ saturation of the plasma ironbinding capacity.

The use of these chelating agents for the diagnosis and treatment of conditions associated with iron overloading is discussed.

I am grateful to the physicians of the Hospital for Sick Children for allowing me to study their patients. Dr. P. R. Evans also referred Cases 6 and 10 from Guy's Hospital for inclusion in the investigation. I am also indebted to Dr. R. M. Hardisty for much helpful criticism. Mr. D. L. Williams, of the Radcliffe Infirmary, Oxford, suggested the method used for the estimation of iron in urine: the determinations were carried out by Mrs. Shirley Lichtigfeld. I should like to thank Dr. K. R. Keay, of Ciba Laboratories Ltd., for the supply of "desferal"; and Dr. J. P. Birkett, of Geigy Pharmaceutical Company Ltd., for the D.T.P.A.

This work was carried out during the tenure of a Research Fellowship supported by the Joint Research Board of the Hospital for Sick Children and the Institute of Child Health.

\section{REFERENCES}

Bannerman, R. M., Callender, S. T., Hardisty, R. M., and Smith, R. S. (1962a). To be published

and Williams, D. L (1962b). Brit. med. J., 2, 1573.

H., and Mallett, B. (1955). Biochem

"Experience to Date with Desferrioxamine in the Treatment of Diseases Involving a Pathological Deposition of Iron in the Organism." Report of a meeting of clinical
investigators at Basle.
Ellis, J. T., Schulman, I., and Smith, C. H. (1954). Amer. J. Path., $30,287$.

Erlandson, M. E., Walden, B., Stern, G., Hilgartner, M. W., Wehman, J., and Smith, C. H. (1962), Blood, 20, 359

Fahey, J. L., Rath, C. E., Princiotto, J. V., Brick, I. B., and Rubin, M. (1961). J. Lab. clin. Med., 57, 436.

Ramsay, W. N. M. (1957). Clin. chim. Acta, 2, 214, 221.

Whipple, G. H., and Bradford, W. L. (1936). J. Pediat., 9, 279 Witzleben, C. L., and Wyatt, J. P. (1961). 82, 1 .

\section{GREATER-CURVATURE GASTRIC} ULCERS IN PATIENTS ON LONG-TERM STEROID THERAPY

\author{
BY \\ F. M. LOW, M.B., D.M.R.D. \\ From the $X$-ray Department, The Radcliffe Infirmary, \\ United Oxford Hospitals
}

The belief that the majority of greater-curvature ulcers are malignant has been held for many years (Williams, 1941 ; Blum, 1944). Cave (1948) quoted some early Mayo Clinic figures which stated that $100 \%$ of greatercurvature ulcers were malignant. This belief has been fostered by the rarity of benign peptic ulceration of the greater curvature, the frequency of neoplasm at that site, and the difficulty of determining with certainty the nature of the ulcer on the greater curvature. This paper records four cases of benign greater-curvature gastric ulcer in patients on long-term steroid therapy.

\section{Case 1}

A man, then aged 24, was first admitted to hospital in June, 1953, for investigation, with a six-months history of a polyarthritis, and Raynaud's phenomenon affecting all limbs. No primary cause for the Raynaud's phenomenon could be found, and he was discharged on analgesics and tolazoline hydrochloride. He was readmitted to hospital in December of the same year, complaining of thickness and tightness of the skin of his neck and arms: he showed the typical skin changes of scleroderma. Treatment was changed to A.C.T.H. 25 units intramuscularly every six hours ; this dose was subsequently reduced, and at the time of his discharge 10 weeks later it was 10 units intramuscularly twice daily. The condition of his skin had improved.

His condition remained satisfactory until November, 1954 , when an exacerbation of his polyarthritis necessitated readmission to hospital. The dosage of A.C.T.H. was increased to 20 units intramuscularly twice daily, and this was continued after his discharge. In November, 1956, cortisone, one $25-\mathrm{mg}$. tablet twice daily was started in addition to the A.C.T.H. Symptomatically he was much better.

In July, 1959, he was again admitted to hospital, with a five-day history of sore throat, substernal pain, and rigors. No cause was found for these symptoms, but he responded quickly to tetracycline and intravenous cortisone. This was subsequently changed to oral cortisone, and on discharge four weeks later he was on a maintenance dose of cortisone $300 \mathrm{mg}$. daily (three 25-mg. tablets four times daily); the dose of A.C.T.H. was unchanged. Cortisone was later reduced to $200 \mathrm{mg}$. daily ; attempts to reduce this further resulted in increased severity of his joint pains. In September he was back at work, and feeling fitter than for a long time.

In February, 1960, at a routine out-patient attendance, he complained of heartburn, which he had noticed over the past month. This often came on after stooping or lying. At this attendance his blood-pressure was $180 / 120$, and for this reason the cortisone was changed to prednisone $40 \mathrm{mg}$. daily (two 5-mg. tablets four times daily after meals). In 